\title{
science
}
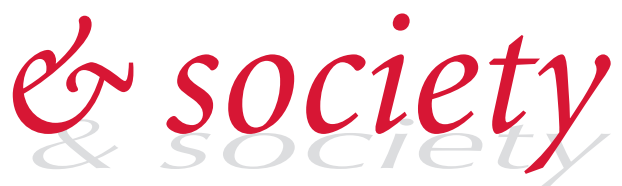

\section{Humanity 2.0?}

\author{
Enhancement, evolution and the possible futures of humanity
}

\section{Sarah Chan}

$\mathrm{H}$ umanity is constantly reinventing itself. From the earliest days of our species, when one of our ancestors picked up a burning stick and kindled it into a fire, to the present day, when we search for the 'God particle' and clone sheep, cats, dogs and more, humans have been altering their environment and shaping the world around them. The history of our species is a stream of discoveriesmajor and minor-which have allowed us to progress and direct, to some extent, the course of our evolution.

Probably the most important technological advances in recent history have been those produced by biomedical science. Our ever-increasing understanding of human biology, and the consequent ability to treat and prevent disease, have improved healthcare phenomenally during the past century. The emerging medical technologies suggest even greater possibilities for the relatively near future such as stem-cell therapy and regenerative medicine, genetic manipulation and new pharmacological agents.

\section{The history of our species is a stream of discoveries-major and minor-which have allowed us to progress and direct the course of our evolution}

But why should we limit ourselves only to treating disease and injury? These same technologies actually hold the potential to allow us to improve further upon myriad aspects of human function-that is, to enhance current and future generations. This possibility has raised considerable debate: Is human enhancement acceptable and how far should we go in pursuit of this goal? What will the use of enhancement technologies mean for the future of humanity, and what exactly do we mean when we speak of humanity?

n this paper, I address the ethical issues associated with human enhancement, including what types of enhancement might be acceptable; whether there is a meaningful difference between medical treatment and enhancement; and whether enhancement, far from being ethically questionable, is a morally preferable goal. In particular, I consider how we might view human enhancement in the context of our past, present and future evolution.

\section{But why should we limit ourselves only to treating disease and injury?}

A prominent concern about enhancement technologies is that their use might compromise our humanity and transform us into something other than-and perhaps beyond-human, thereby jeopardizing our species. These concerns, I would argue, are misplaced, as I hope will become clear. An examination of the potential impact of enhancement technology on humans and humanity might lead us to view enhancement in a different light and help to define what it means to be human. In fact, the use of enhancements-genetic or otherwisewill not cause us to cease to be human or to lose the essential qualities of humanity; indeed, enhancements and the desire to use them might be seen as an expression of our humanity. The advent of human genetic enhancement, then, signifies not the end of the human race, but rather, the next step in the continuing process of human evolution.
So, what is enhancement? I propose that human enhancement is anything that improves our function: any intervention that increases our general abilities and allows the individual to flourish. In other words, an enhancement is something that is of benefit to the individual-as the British philosopher John Harris puts it: "If it wasn't good for you, it wouldn't be enhancement" (Harris, 2007).

nhancement might be something that is a normative good: something that we would reasonably suppose a rational person would prefer to have. Many proposed enhancements fall into this category, including increased intelligence and better health. But an enhancement might also be beneficial for a particular individual because it fulfils a preference or desire, even if it is something that we might judge to be of neutral value or even detrimental by normative standards. Such enhancements might include minor cosmetic or aesthetic alterations. By contrast, major invasive cosmetic procedures or the use of steroid drugs to enhance athletic performance, although they might fulfil a preference, could be thought to have dubious benefit. I will defer the question of exactly where the line should be drawn between supporting preference-fulfilment and the exercise of autonomy, and the possible expense to the health and well-being of a person, as others might see it-or indeed whether any such line should be drawnexcept to note that the choices of the individual ought to be given substantial, if not absolute, weight in these matters. An enhancement is something that is good for us, and that we think is good for us.

The types of technology that are often discussed in ethical debates about human enhancement-such as genetic manipulation, pharmacological agents and cybernetic 
modifications-are new. However, once we disentangle the ethical concerns from the mere technophobia that is often associated with the application of new discoveries, it becomes clear that we already accept and actively encourage the use of many technologies that ought to be described as enhancement. For example, many of us take dietary supplements to improve health and prevent disease, we supply prosthetic limbs to the disabled, participate in vaccination programmes to enhance our natural immunity to infectious disease, use hearing aids or cochlear implants to treat deafness and use spectacles to correct defective vision, all of which represent enhancements.

It might be argued that some of these constitute medical treatment rather than enhancement, but is this a meaningful moral distinction? Consider the example of corrective lenses, spectacles or laser surgery, all of which we use to treat eyesight defects-presumably they would be called 'therapies' or 'treatments'. I doubt that any of us find the wearing of glasses morally offensive, despite the enhancing properties of these technologies. Yet what about the use of binoculars and telescopes-these undoubtedly greatly enhance, rather than just 'treat', our eyesight (Harris, 2007). Do we think that birdwatchers and astronomers are morally deficient, whereas mere wearers of glasses are free from such guilt? Equally, many therapies might, by their application, result in enhancement as well as treatment. The types of regenerative therapy based on stem cells might not only cure, but also improve the condition of a patient. Would it then be unacceptable to use them because they are too effective?

It is difficult to see how there could be a moral difference, at an individual level, between improving reduced function to normal levels and improving normal function to super-normal levels. At an individual level, the concept of normalcy lacks both precision and moral content: the 'normal' state for one person might be a state of disability for another or a state of enhancement for someone else. For example, an average human might run at $15 \mathrm{~km} / \mathrm{h}$; by contrast, Australian gold medallist Cathy Freeman can run at nearly $30 \mathrm{~km} / \mathrm{h}$, whereas someone suffering from severe muscular dystrophy might not be able to run at all. Of course, Freeman is well above average in terms of natural athletic abilities; indeed, were we against enhancement, we might consider that her specialized training to increase those abilities further was a morally

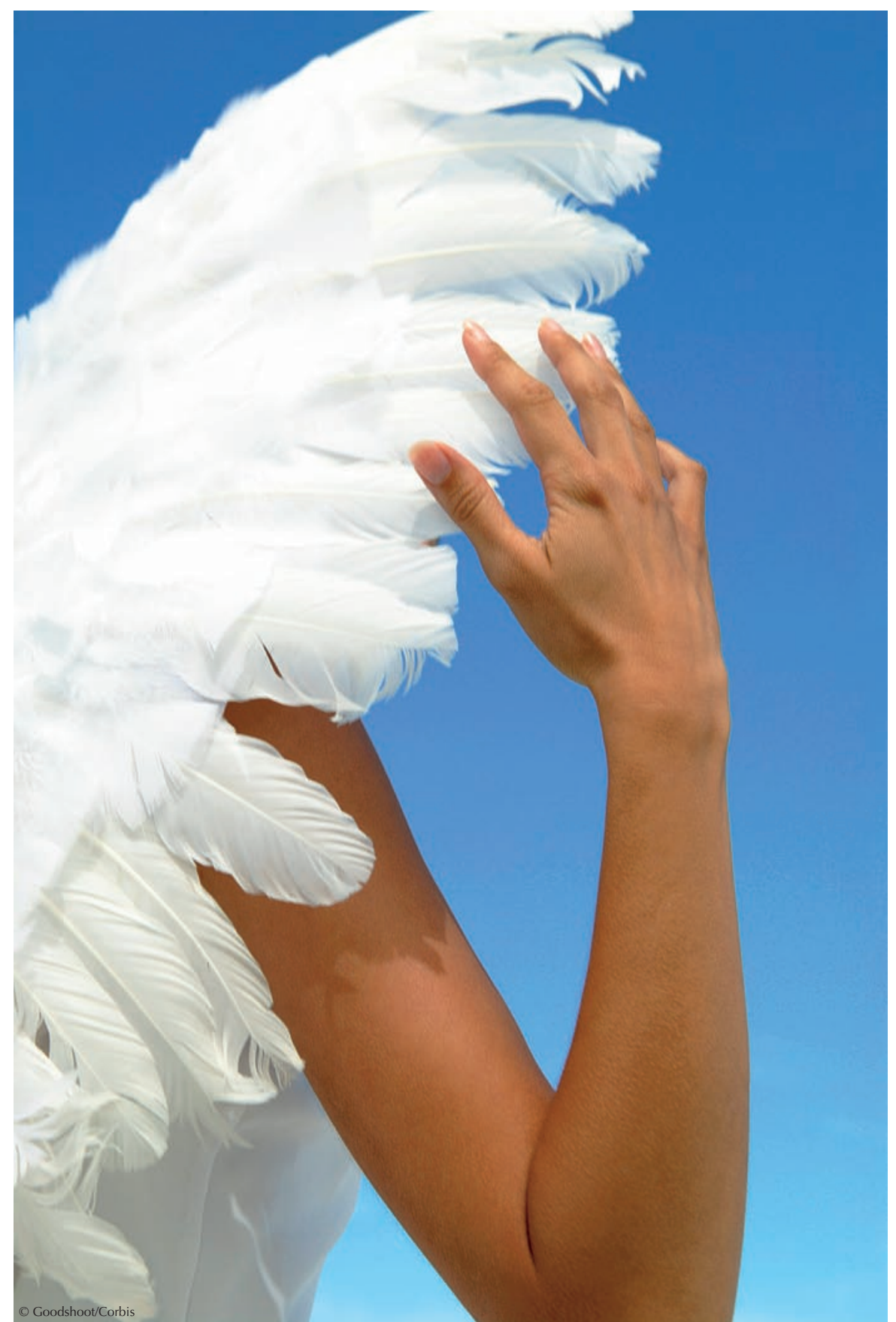

questionable act in itself. Restoring to average, therefore, cannot be the goal or definition of therapy, otherwise, treating Freeman's heel injury would have constituted enhancement, and disabling someone from above average to an average level would be 'therapeutic'. Moreover, if we were to set 'average' as our benchmark for normal, we would be obliged to provide amputees with incomplete prostheses, as the average number of legs is slightly less than two. t is true that only having one leg is a disability and that muscular dystrophy is a disease, so these conditions are not normal. Yet, basing our definitions of therapy and enhancement on what is normal, and basing what is normal on ideas of disability or disease, means that where we draw the line between therapy and enhancement depends on how we define disability and disease. Proponents of the idea of "species-typical function" (Boorse, 
1975) as a benchmark for distinguishing between treatment and enhancement often ignore the facts that many interventions considered to be treatment actually alter typical function, and that the present definition of normal includes many species-atypical features: living to the age of 60 years in good health, for example, which is something that many of us can reasonably hope for. The concept of what we think of as normal has changed over time, through altered environmental and genetic factors. In a health context, better nutrition, scientific knowledge and the intervention of modern medicine have all produced improvements to the normal condition (Chan \& Harris, 2007).

\section{An enhancement is something that is good for us, and that we think is good for us}

Those who believe that human enhancement contradicts our moral values will, therefore, either have to show that the current benefits of modern medicine and science-which they call therapies-are somehow implicitly different to those that we might develop in the future-which they call enhancements - or reject all the enhancements that we already enjoy, on pain of moral hypocrisy.

$\mathrm{P}$ articular concern about human enhancement often seems to focus on genetic manipulation and the undesirability of using it to enhance our children or ourselves. As I have argued above, however, there is nothing wrong with enhancement per se. Opponents of genetic enhancements, therefore, must show that there is something particular about the use of genetic technologies that renders these enhancements unacceptable, whereas the use of chemical or mechanical enhancements is not.

Genetic manipulation might be perceived as less acceptable because it is a relatively new procedure-at least when applied to human beings-and therefore carries the possibility of unforeseen risks. Gene therapy, in particular, has received bad press after a few cases in which potential dangers did manifest. Examples include the genetherapy trials to treat severe defects of the immune system that resulted in leukaemia (Cavazzana-Calvo et al, 2000) and the death of Jesse Gelsinger, who suffered an adverse reaction to the virus used as a vector in gene therapy against ornithine transcarbamylase deficiency (Savulescu, 2001).

The presence of risk is not a factor unique to genetic enhancement-it is also likely that other types of enhancement technology have risks associated with their application, as do current drug therapeutics. Every new treatment involves some amount of risk; this, in itself, does not render it unethical. If we were to avoid every activity that carried any amount of risk, no matter how small, then we would never drive motor cars, cross the road or even get out of bed in the morning. The most ethical course of action in the face of risk is to evaluate the balance of risk and benefit, and attempt to minimize the risks where they must be faced. This might not be an easy thing to do in the case of new technologies, but it is better done than not.

So is there anything intrinsically wrong with genetic manipulation? There certainly cannot be a moral proscription against modifying the somatic genome: we are at liberty to make changes to our physical bodies in terms of their appearance, condition or health, and DNA is simply a part of that-in fact, somatic mutation occurs all the time.

A rguments against human genetic modification have therefore concentrated in particular on the ethical unacceptability of germ-line gene therapy. The distinguishing feature of germ-line genetic modification - as opposed to somatic genetic modification-is that any changes made to the genome will be heritable and therefore affect not only the individuals treated, but also their descendants - and by extension, the future human race as a whole.

The argument invoked is that it is wrong to make genetic choices for our descendants. One reason given for this is sometimes expressed in terms of the "right to an open future" (Feinberg, 1980): that is, by predetermining the genes of our children, we are somehow limiting their own right to choose. Choosing the genes of our children, so the argument goes, deprives them of the right to make their own choices about their lives and thereby infringes their autonomy (Buchanan et al, 2000; Davis, 2001; Habermas, 2003; Mameli, 2007).

Yet children can never exert a choice over the genes that they are born with, regardless of whether their parents do. Those who believe in genetic determinism must realize that abandoning our children to the mercy of the 'genetic lottery' does not free them from the tyranny of their genes, rather, it merely removes any element of choice on the part of anyone as to what those genes are. Those of us, by contrast, who look beyond genetic determinism to see that it is far more than genes that determine the future of our children, will probably also realize that- to the extent that genes do determine some aspects of our lives, in particular our health and associated quality of life-it is surely far better to have a predisposition to a healthy life than to risk a higher chance of suffering and disease.

\section{...enhancements and the desire to use them might be seen as an expression of our humanity}

The corollary to the above argument is that parents themselves should not seek to make such choices and that attempting to enhance children represents "a kind of hyperagency - a Promethean aspiration to remake nature, including human nature, to serve our purposes and satisfy our desires" (Sandel, 2004, 2007). According to this argument, parental virtue requires acceptance rather than control and an "openness to the unbidden", rather than the "hubris [of] an excess of mastery" - that is, an appreciation of the 'gifted' nature of human achievement, rather than an aspiration to increase these achievements. Choosing to enhance is therefore wrong both because it violates the principles of good parenting and because of the negative social consequences that will follow the abandonment of such principles.

In each case, however, it is not clear whether the availability or use of genetic enhancements will result in the predicted disintegration of social values, or if allowing parents to make choices about their children contravenes the requirements of parental responsibility. It is true that the use of geneticenhancement technologies will involve parents making decisions about the genetic heritage of their children. However, once the technology exists and has been proven to be safe, to refrain from using it is likewise to make a decision about the genetic inheritance of our descendants-specifically: that they will not receive such enhancements and will be denied the consequent benefits. If we were to have the choice of eradicating a serious disease for future generations and decided against doing so, I doubt that our descendants would thank us for it. Abdicating choice is not the action of a responsible parent; exercising choice wisely is. 
$\mathrm{O}$ course, this applies equally to both genetic and non-genetic interventions. Every parent wants to have a healthy child and there is nothing wrong with this. Indeed, we might look askance at a parent who did not claim to want the best for their children. Yet what do we mean by healthy? The only logical answer to this question is 'as healthy as possible'. For example, we know that certain maternal behaviours during pregnancy can have adverse consequences for child health: the use of alcohol and tobacco increase the risk of low birth weight and associated developmental delay, and poor maternal diet can increase the chances of developing type 2 diabetes in later life. We encourage mothers-to-be to improve the health of their children by avoiding these things; indeed, we consider them to be irresponsible if they fail to do so. Similarly, we advocate folate supplements as a positive measure to decrease the risk of spina bifida. Therefore, we see it as a strong obligation on parents to use the available knowledge and medical technology to maximize the health of their children. We also encourage the use of vaccination and other choices for children that protect and benefit them.

Surely, then, this argument also applies to genetic enhancement. If we could, with safety and certainty, engineer our children to have immunity to viral infection, protection from heart disease and reduced susceptibility to cancer, we should do so. In other words, not only is genetic enhancement morally acceptable, but, if and when it becomes safe and affordable, there will be a moral imperative to use it for the benefit of future generations (Chan \& Harris, 2007).

M ore general concerns about genetic manipulations focus on the consequences of genetic enhancement for the future of the human race. These concerns include worries about the loss of genetic diversity: that we will become a race of clones - either literally, through the use of reproductive cloning to create armies of identical beings, or because our uniform desire for enhancements will result in overall genetic uniformity. Others seem to have the opposite fear: that changing our genome and creating genetic differences will lead to the fragmentation and destruction of the human race. The American bioethicist George Annas, for example, has described genetic engineers as "potential bioterrorists" because of the possibility of genocide based on engineered genetic differences (Annas, 2001). The
United Nations Educational, Scientific and Cultural Organization (UNESCO) Universal Declaration on the Human Genome states that, "the human genome must be preserved as the common heritage of humanity" (UNESCO, 1997). However, the only way to eradicate all genetic differences that might lead to genocide, and the only way to preserve the human genome exactly as it is today, is universal human reproductive cloning-a course of action that neither Annas nor UNESCO would be likely to favour.

\section{With the new biological technologies offered to us, we might be able to overcome the drag in our own bodies}

These arguments, then, are confusing and contradictory, yet they strike a note of concern with many. Even if this concern is misplaced or misdirected, we might well wonder what the consequences of enhancement will be for humanity as a whole.

We are familiar with the idea of Darwinian evolution: natural selection acting on genetic variation to produce long-term changes in our genetic make-up. There is also a sense in which human society and culture can be said to undergo evolution, as ideas that are more successful—whether because they are correct or intuitively attractive or both-will propagate themselves: a process known as meme evolution. This, of course, includes the progression of technological ideas.

It is reasonable to say that the relationship between humans and technology has probably influenced the course of our genetic and cultural evolution in the past. For example, it seems likely that the technological developments since pre-history have changed the selection pressures acting on human beings - one can plausibly suppose, for example, that the transition from huntergatherer to agricultural societies would have altered the environment to allow different genes to be favoured. Moreover, technology has undeniably influenced the course of social development.

It is often said, with reference to the human race, that we have halted evolution by doing away with natural selection. It is true that modern medicine allows many individuals to survive and reproduce when they might not otherwise have done so; yet, we must remember that the marked reductions in infant mortality, deaths from disease and so on are only a product of the past century or so-a mere few generations. In the context of the roughly three billion year history of life on Earth, it seems to be a little premature to declare victory over natural selection-although we are probably the first and only species that understands evolution and might be in a position to influence its course deliberately.

Even if we were to remove the influence of natural selection entirely, it would not necessarily mean the end of evolution - if by evolution we mean social change or cultural evolution - or the end of genetic change. In fact, although the collective human genome is not changing appreciably faster than it has in the past, the development of human society as a whole- - that is, evolution in the cultural sense-is progressing faster than ever, and is constantly accelerating. What we want to do and what we dream of doing is rapidly outpacing what we can do with the genomes and the bodies that we are presently born with. Hans Moravec, who is a robotics expert at Carnegie Mellon University (Pittsburgh, PA, USA), has expressed this as, "the drag of the flesh on the spirit [...] the problem is that cultural development proceeds much faster than biological evolution" (Moravec, 1989). Interestingly, he noted this in the context of artificial intelligence and wondered whether machines might overcome the "drag of the flesh" from which humans suffer. With the new biological technologies offered to us, we might be able to overcome the drag in our own bodies.

M odifying the human genome might be one way of doing this. Some see it as tampering with the process of natural evolution that produced the human genome in its current form. True enough, our present genome is, by definition, a successful one: it is still around today. However, evolution so far has operated somewhat in the dark. The happenstance of natural evolution has also bequeathed us a legacy of genetic failings: susceptibility to disease, cancer and the depredations of old age, to name but a few. We are, as the British evolutionary scientist Richard Dawkins might put it, stranded on our own particular peak of 'Mount Improbable' (Dawkins, 1996), lumbered with all the genetic encumbrances of our evolutionary history, good and bad.

We have, almost within our reach, the power to transcend this situation: to change our genotypes, much as we can already change our phenotypes to improve health 
and quality of life. There might be no guarantee of success; however, in comparison to natural evolution, any genetic modifications aimed at improving the human condition will at least be evidence-based rather than random, and unless blind watch-making is to be the new gold standard in scientific research, that is as good as it gets with current technology (Chan \& Harris, 2006).

How will this new "enhancement evolution" (Harris, 2007) be mediated? The prospect of genetic enhancement is always haunted by the spectre of eugenics - the state-coerced use of technology to change us whether we will or no. To this point, we should emphasize once again the importance of individual choice. Yet, enhancements might also limit individual choices through the so-called genetic arms race, in which everyone is forced to use enhancements to 'keep up with the Joneses'. Is this a bad thing? Evolution, again, has always been a genetic arms race: we are designed to compete. The end point in this case, however, is not the threat of mutually assured destruction, but rather the survival of our species. Of course, we should have the option not to participate, to refuse enhancements. Yet why would we want to? If the ultimate result of these technologies is better lives for all humans, then their use is probably a good thing. Put another way, we currently engage in a type of educational arms race of enhancements. Reading and writing was once the province of a few privileged scholars; now it is almost mandatory to equip children with these skills, if they are to keep up with their peers. The result of this educational arms race has been almost ubiquitous literacy—surely a benefit?

$\mathrm{E}$ ven these sort of claims, however, really only apply to the developed and industrialized world. The 'ubiquitous' benefits that we enjoy are often not readily available to those in developing nationsand in this sense, enhancements raise crucial questions of justice. Will the ultimate result of human enhancement be better lives for everyone, or will it be better lives for a few at the expense of the disadvantaged many?

The issue of how to address the aims of justice with respect to enhancement technologies is a complex one, and I have scope only to note two brief points here. The first is that concerns about justice do not warrant turning our backs entirely on enhancement technologies - "it is doubtful ethics to deny a benefit to some unless and until it can be provided to all" (Harris, 2007). Certainly, that is not the position we take on most new technologies. Allowing access to expensive technologies to those who can afford them will, in all likelihood, speed their development to become more readily available to everyone. The second point is that this process might need a helping hand: if we see injustice, we should move to address it in a positive way, to 'level up', so that the same opportunities are available to all, rather than 'levelling down' and reducing everyone to the same level.

A few last words, then, on what enhancement might mean for humanity. Enhancement technologies, provided their application is correctly managed, will ultimately be of benefit to humankind and, as such, we have good moral reasons to pursue them. They will not, as some fear, destroy humanity by turning us into something other-something more-than what we are. We have always wanted-and will probably always want- to be more than we are. Yet by the same token, we will always remain 'what we are' - in the sense of that which really matters to us, that which makes us human. Surely, being human and the definition of 'humanness' should not depend arbitrarily on a particular combination of abilities and limitations - to run no faster than 25 miles per hour, to live no longer than a century. Indeed, logically it cannot depend on such limitations, or we would be forced to admit that we ourselves are no longer human compared to our predecessors who had more limited abilities and life spans.

Instead, what make us human are our aspirations, our awareness of ourselves as beings in the world (including our limitations), our ability for self-contemplation and reflection, and the desire to attempt to change what we see. We are not designed to remain "passive, inert players in the game of life" (Chan \& Harris, 2007). What makes us uniquely human is the ability to shape our own destinies according to our desiresand genetic and other enhancement technologies provide further means for us to do so. In this sense, enhancements and the desire to avail ourselves of them are an expression of our essential humanity.

The advent of new forms of human enhancement on our technological horizon does not therefore signify, as some have warned, the end of humanity. Rather, it is just the next step in a continuing process: that of human evolution, which stretches far back into the dim past and, we might hope, will continue into the future for many thousands of years to come.

\section{REFERENCES}

Annas G (2001) Genism, racism and the prospect of genetic genocide. Presentation at UNESCO 21st Century Talks: World Conference Against Racism, Racial Discrimination, Xenophobia and Related Intolerance in Durban, South Africa, September 3rd. www.thehumanfuture.org

Boorse C (1975) On the distinction between disease and illness. Philos Public Aff 5: 49-68

Buchanan A, Brock DW, Daniels N, Wikler D (2000) From Chance to Choice: Genetics and Justice. Cambridge, UK: Cambridge University Press Cavazzana-Calvo M et al (2000) Gene therapy of human severe combined immunodeficiency (SCID)-X1 disease. Science 288: 669-672

Chan S, Harris J (2006) The ethics of gene therapy. Curr Opin Mol Ther 8: 377-383

Chan S, Harris J (2007) In support of enhancement. Studies in Ethics Law and Technology 1: Article 10

Davis DS (2001) Genetic Dilemmas. New York, NY, USA: Routledge

Dawkins R (1996) Climbing Mount Improbable. London, UK: Penguin Books

Feinberg J (1980) The child's right to an open future. In Whose Child? Children's Rights, Parental Authority and State Power, W Aiken, H LaFollette (eds), pp 124-153. Totowa, NJ, USA: Rowman and Litlefield

Habermas J (2003) The Future of Human Nature. Cambridge, UK: Polity

Harris J (2007) Enhancing Evolution. Princeton, NJ, USA: Princeton University Press

Mameli M (2007) Reproductive cloning, genetic engineering and the autonomy of the child: the moral agent and the open future. / Med Ethics 33: 87-93

Moravec H (1989) Human culture: a genetic takeover underway. In Artificial Life, CG Langton (ed). Indianapolis, IN, USA: Addison-Wesley Sandel MJ (2004) The case against perfection: what's wrong with designer children, bionic athletes, and genetic engineering. At/ Mon 292: 50-54, $56-60,62$

Sandel MJ (2007) The Case Against Perfection: Ethics in the Age of Genetic Engineering. Cambridge, MA, USA: Belknap

Savulescu J (2001) Harm, ethics committees and the gene therapy death. J Med Ethics 27: 148-150

UNESCO (1997) Universal Declaration on the Human Genome and Human Rights. Paris, France: UNESCO

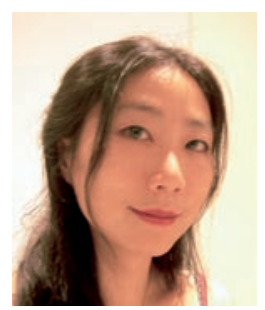

Sarah Chan is a Research Fellow at the Institute for Science, Ethics and Innovation at the University of Manchester, UK.

E-mail: sarah.chan@manchester.ac.uk doi:10.1038/embor.2008.105 